\title{
Application of Servqual Model on Measuring Service Quality: A Bayesian Approach
}

\author{
Dr. K. Ravichandran, \\ Assistant Professor, College of Business Administration in Alkharj, \\ King Saud University, P O Box 165, 11942, \\ Alkharj, Saudi Arabia. Email: varshal2@yahoo.com

\begin{abstract}
Dr. S. Prabhakaran,
Assistant Professor, College of Business Administration in Alkharj,

King Saud University, P O Box 165, 11942,

Alkharj, Saudi Arabia. Email: jopraba@gmail.com
\end{abstract}

\author{
Mr. S. Arun Kumar, \\ Assistant Professor, Department of Management Studies, \\ Saranathan College of Engineering, Trichy, \\ Tamilnadu, India. \\ email:arunkanthh@yahoo.co.in
}

\begin{abstract}
Financial liberalization has led to intense competitive pressures and private banks dealing in retail banking are consequently directing their strategies towards increasing service quality level which fosters customer satisfaction and loyalty through improved service quality. This
\end{abstract}


article examines the influence of perceived service quality on customer satisfaction suing an adaptive Bayesian frame work in private sector banks Bayesian structural regression estimates are shown to provide a banking institution with reliable information for use in positioning the private banks in its market place.. The article concludes that increase in service quality of the banks can develop customer satisfaction which ultimately retains valued customers.

Keywords: Perceived Service Quality, SERVQUAL, customer satisfaction, BSR, Structural Regression

\section{INTRODUCTION}

Private Banks dealing in retail banking Industry is consequently put into lot of pressures due towards increase in global competition. Various strategies are formulated to retain the customer and the key of it is to increase the service quality level. Typically, customers perceive very little difference in the banking products offered by private banks dealing in services as any new offering is quickly matched by competitors. Parasuraman et. al (1985) and Zeithaml et., al (1990) noted that the key strategy for the success and survival of any business institution is the deliverance of quality services to customers.

The quality of services offered will determine customer satisfaction and attitudinal loyalty. The inter relationships of variables defining the antecedents and also the consequences of customer satisfaction have been studied extensively in the consumer research literature ( e.g., Anderson and Sullivan 1993; Bearden and Teel 1983; Bolton and Drew 1991a, 1991b; Cardozo 1965; Churchill and Surprenant 1982; Cronin and Taylor 1992; Greg M. Lepak 1998; LaTour and Peat 1979; Oliver 1977,1980; Oliver and DebSaro 1988; Tse and Wilton 1988; Westerbrook 1982; Yi 1990), However, there appears to be conflicting evidence as to the nature of the linkages between the antecedents and consequences of satisfaction. 


\subsection{About private retail banking in India}

Initially all the banks in India were private banks, which were founded in the pre-independence era to cater to the banking needs of the people. In 1921, three major banks i.e. Banks of Bengal, Bank of Bombay, and Bank of Madras, merged to form Imperial Bank of India. In 1935, the Reserve Bank of India (RBI) was established and it took over the central banking responsibilities from the Imperial Bank of India, transferring commercial banking functions completely to IBI. In 1955, after the declaration of first-five year plan, Imperial Bank of India was subsequently transformed into State Bank of India (SBI). In 1994, the Reserve Bank of India issued a policy of liberalization to license limited number of private banks, which came to be known as New Generation tech-savvy banks. Global Trust Bank was, thus, the first private bank after liberalization; it was later amalgamated with Oriental Bank of Commerce (OBC).

At present, Private Banks in India includes leading banks like ICICI Banks, ING Vysya Bank, Jammu \& Kashmir Bank, Karnataka Bank, Kotak Mahindra Bank, SBI Commercial and International Bank, etc. Undoubtedly, being tech-savvy and full of expertise, private banks have played a major role in the development of Indian banking industry.

\subsection{Review of Literature}

Many scholars and service marketers have explored consumers' cognitive and affective responses to the perception of service attributes in order to benefit by providing what consumers need in an effective and efficient manner. Consumer satisfaction (e.g. Cadott et al, 1987; Churchill \& Surprenant, 1982; Fornell,1992; Oliver, 1997) and PSQ (e.g. Parasuraman et al, 1985, 1988; Rust \& Oliver, 1994; Zeithaml et al, 1996) have been considered the primary intervening constructs in the area of service marketing because ultimately they lead to the development of consumer loyalty or re-patronization of a product or service.

Consumer perception of service quality is a complex process. Therefore, multiple dimensions of service quality have been suggested (Brady \& Cronin, 2001). One of the most popular 
models, SERVQUAL, used in service marketing, was developed by Parasuraman et al (1985, 1988). SERVQUAL is based on the perception gap between the received service quality and the expected service quality, and has been widely adopted for explaining consumer perception of service quality. Originally 10 dimensions of service quality were proposed (reliability, responsiveness, competence, access, courtesy, communication, credibility, security, understanding the consumer, and tangibles). Later these were reduced to five (reliability, responsiveness, empathy, assurances and tangibles).

There is general agreement that the aforementioned constructs are important aspects of service quality, but many scholars have been skeptical about whether these dimensions are applicable when evaluating service quality in other service industries (Finn \& Lamb, 1991; Cronin \& Taylor, 1992). For example, Cronin \& Taylor (1992) argued that the evaluation of service quality based on the expectation-performance gap derived from Parasuraman et al $(1985,1988)$ is insufficient because much of the empirical research supported performancebased measures of service quality. This has more explanatory power than measures that are based on the gap between expectation and performance (e.g. Babakus \& Boller, 1992; Babakus \& Mangold, 1992; Churchill \& Surprenant 1982). In addition, Kang \& James (2004) argued that SERVQUAL focuses more on the service delivery process than on other attributes of service, such as service-encounter outcomes (i.e. technical dimensions). In other words, the SERVQUAL measurement does not adequately explain a technical attribute of service.

Thus many scholars have argued that the components of SERVQUAL could not fully evaluate consumer perception of service quality in certain industries (Cronin \& Taylor, 1992; Finn \& Lamb, 1991). Grönroos (1984) suggested two attributes of service which have been identified as dimensions of service quality based on the conceptualization of service quality as between perceived service and expected service. As an extension of Grunions' model, Rust \& Oliver (1994) provided a three-component model explaining service quality through service product, service delivery and service environment, while Brady \& Cronin (2001) suggested three service quality dimensions - service outcome, consumer-employee 
interaction and service environment. The notion of service product/service outcome and service delivery/consumer-employee interaction is consistent with the idea of technical attribute and functional attribute derived from Grönroos' model.

The interrelationships of variables defining the antecedents and also the consequences of customer satisfaction have been studies extensively since last 25 years (Anderson and Sullivan 1993; Churchill and Superenanat 1982; Cronin and taylor 1992; Greg M. Lepak 1998; La Barbera and Mazursky 1983; La Tour and Peat 1979; Oliver and Bearden 1985; Oliver and De Sarbo 1988; Westerbrook 1981; Yi 1990).

The purpose of the present study is to present a Bayesian Structural Regression (BSR) paradigm for modeling service quality of banking services using the Servqual model. Unlike previous research, this study uses adaptive structural methods to model the servqual items. These methods are based on conjugate Bayesian theory discussed by Dempster (1969) and made operational by Chen(1979) using the EM method ( Dempster, Laird and Rubin 1977). The Bayesian approach provides a mechanism for incorporating prior structural information in to covariate estimation. This information can be either vague or specific and is used only to the extent that it reflects worthwhile information and about the interrelationships among the variables as possible.

\section{Overview of Bayesian Structural Regression}

Chen (1979) developed a class of methods for stochastic multiple regression where the criterion and predictor variable are jointly random. The BSR approach uses adaptive smoothing procedures and maximum likelihood estimation to produce stable representations of the predictor-criterion covariance structure. For more information see the article by Pruzek and Lepak (1992) which discusses techniques in covariance and regression estimation that were motivated by Chen's work. However, Pruzek and Lepak developed adaptive smoothing and estimation techniques using frequentist principles where estimation is techniques using frequentist principles where estimation is non-iterative and generally does not involve 
maximum likelihood estimation.

In particular, adapting the conjugate Bayesian procedure for joint covariance and mean estimation (see Dempster 1969), the BSR methodology assume that a system of n observation vectors (each composed of one criterion value, and $j=p-1$ predictor values) represents a random sample of $n \quad p$-dimensional values from a multivariate normal distribution with mean $\mu$ and positive definite covariance matrix $\sum$. To simplify discussion, the first observation in each vector is assumed to represent the criterion measurement so that the remaining observation corresponds to measurements on random predictor variables. The derivation of the adaptive Bayesian method is based on the properties of the Wish art distribution. For the conjugate form it is assumed that the inverse of $\sum, \Sigma^{-1}$, has a Wishart prior distribution. Specifically, $\left.\Sigma^{-1} \square \quad(\cdot)^{-1}, v\right)$, with degrees of freedom $v$, It follows the posterior distribution of $\sum$, given the observation vectors, has the inverse Wishart form $\Sigma^{-1}\left(\sum^{*}(n+v)^{-1}, n+v\right)$.

Without prior information for $\mu$, the mean of the posterior distribution of $\sum$ takes the form $\Sigma^{*}=(n+v)^{-1}(v \Omega+n \hat{\Sigma})$, a weighted average of the given prior $\Omega$ and the delta-base matrix $\hat{\Sigma}$, where $\Sigma$ is the usual maximum likelihood estimate (MLE) or $\hat{\Sigma}$.

Chen's (1979) approach was to assume a given structural form for $\Omega$, the mean of the prior distribution of the population covariance matrix $\hat{\Sigma}$, and to estimate the posterior mode (or mean, as a result of symmetry), given the prior structural model. In theory, the prior structure for $\Omega$ can take on any form; however, Chen shows that the $\operatorname{MLE}\left(\hat{\Omega}^{*}, \hat{v}^{*}\right)$ or $(\Omega, v)$ can be obtained by an iterative EM procedure (Dempster, Laird, and Rubin 1977) based on the marginal distribution of $n \hat{\Sigma}$. Chen's main result is a Bayesian estimate of $\Sigma$, defined as the mode of the posterior density of $\sum$ of the form 


$$
\hat{\Sigma}^{*}=\left(n /\left(n+\hat{v}^{*}\right)\right) \hat{\Sigma}+\left(\hat{v}^{*} /\left(\mathrm{n}+\hat{v}^{*}\right)\right) \hat{\Omega} *
$$

In equation (1) $\sum$ is the conventional MLE of $\sum ; \hat{\Omega}^{*}$ denotes a maximum likelihood common factor estimate of the original $\Omega$ and is based on the same data used to generate $\hat{\Sigma}$; and $\hat{v}^{*}$ is a derived posterior estimate which indicates the degree to which structural information in the sample is in agreement with the covariance structural model assumed for $\Omega$. If the prior common factor structure model for $\Omega$ is consistent with the data, $\hat{v}^{*}$ will be large and more weight will be given to the structural covariance estimate $\hat{\Omega}^{*}$. Otherwise, relatively more weight will be shifted to the conventional MLE $\hat{\Sigma}$.

For any set of $j$ predictor variable and a criterion, BSR equations can be derived from the covariance estimate $\hat{\Sigma}^{*}$ in equation (1). Specifically, if $y$ designates the criterion and $x$ the predictors, the $(1 / j)$ symmetrically partitioned estimate

$$
\hat{\Sigma}^{*}=\left[\begin{array}{ll}
\hat{\sigma}_{y y}^{*} & \hat{\sigma}_{y x}^{*} \\
\hat{\sigma}_{x y}^{*} & \hat{\sigma}_{x x}^{*}
\end{array}\right]
$$

Can be used to compute the $j \times 1$ vector of BSR coefficients

$$
\hat{\beta}_{b s r}^{*}=\left(\hat{\Sigma}_{x x}^{*}\right)^{-1} \hat{\sigma}_{x y}^{*}
$$

Where represents the $j \times j$ covariance matrix for the predictor variable, and $\hat{\sigma}_{x y}^{*}$ is the vector of $j$ predictor-criterion covariance. This representation assumes that all variables in the system have been converted to deviation score form. Additionally, Chen (1979, 241-242) use Bayesian arguments to show that $\hat{\beta}_{b s r}^{*}$ has a multivariate t-distribution and gives expressions to compute estimated standard errors for the BSR coefficients.

Several important points for motivating the use of this adaptive Bayesian methodology 
deserve mention. Ordinary least squares (OLS) has been widely used in consumer and marketing research to estimate parameters of linear models. If the criterion and predictor variables in a particular application are random variable measured with error (for example, variable measured by customer perception), then OLS regression coefficients are biased toward zero or attenuated by the measurement error; the squared multiple correlation also will be reduced; and there will be less power in testing whether OLS coefficients are significantly different from zero (fuller 1987). Also, measurement error can lead to difficulty in interpreting OLS regression coefficients because of suppressor effects. For example, if a predictor variable having a positive or zero correlation with a criterion variable is associated with a negative regression coefficient, the predictor variable is a suppressor variable (Darlington 1990). One would certainly expect predictors which have positive correlations with a criterion to also have regression coefficients with positive signs. As a result of measurement error, OLS regression coefficients associated with suppression variable and indeed very difficult to interpret in practices.

To facilitate discussion, equation (1) is rewritten as

$$
\hat{\Sigma}^{*}=w \hat{\Sigma}+(1-w) \hat{\Omega}^{*}
$$

Where $\hat{w}^{*}=n /\left(n+\hat{v}^{*}\right)$. If $w$ in equation (4) is set arbitrarily at unity, then $\hat{\Sigma}^{*}=\hat{\Sigma}$ and $\hat{\beta}_{b s r}^{*}=\hat{\beta}_{\text {ols }}$ thus, the Bayesian approach includes OLS estimation a special case. Suppose that for a particular application $\hat{v}^{*}$ is estimated to represent how well the prior structural model is supported by the data. If prior structural model is unsatisfactory, $w \rightarrow 1$ and the BSR estimates converge to OLS estimates. However, if the prior structural model is strongly supported by the data, then $w \rightarrow 0$ and the BSR estimates are derived primarily form $\hat{\Omega}^{*}$, i.e., the BSR estimates will depend strongly on the parameter estimates of the prior structural mode. Clearly, if $w$ in equation (4) is set to zero, then all BSR results can be generated from the parameters associated with the prior structural model. Of course, complete reliance on a 
particular structural model is unnecessary when adaptive procedures are available.

Thus, the adaptive BSR approach to estimation provides a means to circumvent problems with the use of OLS estimation, especially when prior structural models are chosen to accommodate measurement errors in the variables. Also the use of $\hat{\Sigma}^{*}$ in equation (1) provides a safeguard against the uncertainty associated with the prior structural model selected for $\hat{\Omega}^{*}$. Clearly, the aim is to estimate w adaptively from the data, where $\hat{\Sigma}^{*}$ uses the prior structural model (only) to the extent that observed data support that model. The index $w$ can be viewed as a badness of fit index on a scale from zero to unity, indicating how poorly the prior structural model is supported by the observed data. Accordingly, the complement $(1-w)$ represents a goodness of fit index for the prior structural model.

Common factor analysis models have found useful application in virtually all applied sciences (see lawley and Maxwell (1971) for a useful when it is impossible to obtain wholly reliable measures of constructs; for example, when eliciting customer's perceptions from survey instruments. As shown later, exploratory factor model represent a class of structural models which can facilitate covariance estimation in many situations, especially when there are substantial measurement errors in the variables. When common factor models are used to construct a covariance estimate of $\Sigma$, the prior structural model will generally take the form

$\Omega=F F^{T}+U^{2}$

Where $F$ is the $p \times m$ matrix of common factor coefficients for $p=j+1 ; U^{2}$ represents the diagonal matrix of uniqueness variances; $m$ is the number of common factors; and $T$ denotes the transpose of a matrix. If $m$ is much smaller than $p$ for a population, and the parameters are identifiable, a common factor model may provide a highly parsimonious representation of an observed covariance matrix.

An alternate common factor representation for prior structure can be obtained by assuming 
the independent unique variable have the same variance. Using this assumption, equation (5), is rewritten as

$\Omega=F F^{T}+\sigma I$

Where $I$ is the $p \times p$ identify matrix and $\sigma$ is the common uniqueness variance, $\sigma>0$. This common factor form assumes that the smallest $p-m$ Eigen values of $\Omega$ are equal (Chen 1979, case (II) 244). A useful motivation for this parsimonious structural form is that when the population common factor model with $m$ factor is true, and the uniqueness diagonal is know, then the smallest $p-m$ eigenvalues of interest will equal one another (Lawley and Maxwell 1971). Also as discussed below, the use of the prior structure in equation (6) allows the Bayesian approach to include ridge regression as a special case in its general framework.

Chen uses the prior structure in equation (6) and applies the EM algorithm (Ref. Details for implementing the EM algorithm for this prior structure are outlined by chen (1979), 240). The EM algorithm is guaranteed to converge under the general conditions specified by Dempster, Laird, and Rubin (1977) to obtain the maximum likelihood estimates $\left(\hat{\Omega}^{*}, \hat{v}^{*}\right)$ for use in equation (1).For this case, the adaptive Bayesian covariance estimate in equation (1) is shown to alter the conventional MLE $\hat{\Sigma}$ by shrinking its smallest $p-m$ eigenvalues toward a common quantity, by leaving its first largest $m$ eigenvalues as well as its entire matrix of eigenvectors unchanged. Of course, these results depend on a suitable selection of $m$, the number of common factors. Furthermore, this Bayesian estimate of covariance structure is invariant under any orthogonal transformations.

The maximum, likelihood common factor estimate of $\Omega$ in equation (6) takes the form $\hat{\Omega}^{*}=\hat{F}^{*} \hat{F}^{* T}+\hat{\sigma}^{*} I$ for $\hat{F}^{*}$ of order $p-m$ with $m$ orthogonal factors.

It is noteworthy that given this form for $\hat{\Omega}^{*}$, the BSR coefficient vector in equation (3) can 
expressed as

$\hat{\beta}_{b s r}^{*}=\left(\hat{v}^{*}\left(\hat{F}_{x}^{*} \hat{F}_{x}^{* T}+\hat{\sigma}^{*} I_{j}\right)+n \hat{\Sigma}_{x x}\right)^{-1}\left(\hat{v}^{*} \hat{F}_{x}^{*} \hat{j}_{y}^{*}+n \hat{\sigma}_{x y}\right)$

(Chen 1979, 243-244) where the matrix $\hat{F}^{*}$ is partitioned to correspond to the criterion and predictor variable as

$\hat{F}^{*}=\left[\begin{array}{c}\hat{f}_{y}^{* T} \\ \hat{F}_{x}^{*}\end{array}\right]$

Ridge regression (Hoerl and Kennard 1970) has been extensively used in the marketing literature as a means of deriving stable regression weights from an observed sample covariance matrix. The BSR methods also include ridge regression form explicit. When the number of common factors $m=0$, each term with $\hat{F}_{x}^{*}$ drops out, and $\hat{v}^{*}$ is a scalar multiplier for the diagonal matrix $\hat{\sigma}^{*} I_{j}$. The ridge form is equivalent to assuming that all the eigen values of the prior means of $\Sigma$ are equal. In case the Bays covariance estimates in equation (1) alters the conventional MLE $\Sigma$ by shrinking all its eigen values toward a common value.

Simulations reported by Chen (1979) compare the BSR procedure (including the ridge form) and OLS regression. The simulations are based on a population predictor-criterion covariance (correlation) system with 12 variables (one variable was arbitrarily selected as the criterion variable). The correlations between predictors ranged from 0.12 to 0.77 . The ordered eigen values of the population covariance matrix are $5.02,1.63,0.86,0.77,0.68,0.59,0.53,0.51$, $0.43,0.42,0.34,0.22$. Sample covariance matrices were simulated from this population and $\operatorname{BSR}(\mathrm{m})$ estimates were obtained for fixed $m=0,1,2,3$, under the assumption that the smallest $p-m$ eigen values of the prior means of the population covariance matrix are equal-the same assumption used in this study. Note that the $\operatorname{BSR}(0)$ estimates are ridge regression estimates. Results indicated that the $\mathrm{BSR}(\mathrm{m})$ estimates for all values of $m$ show substantial improvement over OLS estimates in terms of reliability for a sample of size $n=40$ and moderate improvement for a sample of size $n=120$. These sample sizes are not 
uncommon in market responses studies. More importantly, this evidence suggests that the $\mathrm{BSR}(\mathrm{m})$ methods perform well when the number of variables under consideration is large relative to the number of observations, especially when that sample size are limited. The BSR estimates based on common factor models with one and two factors also performed slightly better than the BSR estimates based on three factors and the BSR estimates based on ridge regression. A prior structural model with one or two common factors may be appropriate here since the two largest eigen values of the population covariance matrix appear to be relatively larger than the remaining ten eigen values. Generally speaking, these results suggest that the analysis does not depend critically on the choice for the number of common factors in one's prior structural model. Chen report that similar results have been obtained in other unpublished works. Additionally, he suggests that the BSR methods may not only be robust to violations of distributional assumptions, but also more resistant to outliers that OLS procedures.

We report the empirical findings in the next section.

\subsection{Methodology}

A descriptive research was used to gain an insight into consumer's perceived service quality offered by private banks with respect to five dimensions of SERVQUAL scale. Primary data were collected for the research. An undisguised structured questionnaire, SERVQUAL by (Parusuraman, et al 1985), was used for the research. The sample size used was 500 respondents. Five top private banks in Tirchirappalli District Tamil Nadu, India was selected on the basis of business world Real 500 finance companies ranking statistics (Source: Business World, 2 November 2009, pp.70-72.). The respondents were selected on the basis of convenience sampling. The questionnaire is personally administered to the valued customers both in English and also in their respective vernacular language for better understanding.

\subsection{Service quality \& customer satisfaction Measurement scale used for this study:}

In this research study additional three extra variables has been added to the original SERVQUAL scale, the variables are Service charge charged by the bank, interest rate and 


\section{Macrothink}

Enterprise Risk Management

ISSN 1937-7916

2010, Vol. 1, No. 1: E9

Customer complain handling system suggested by the researcher like (Bahia and Nantel 2000 ; Suresh chander 2002) after careful validation by academicians and industry experts and in the case of the customer satisfactional measurement domain five variables are explicitly extracted from the Behavioral Intention Battery proposed by Zeithaml, Berry and Parasuraman 1996 \& Zeithaml V A 2000). Only customer satisfaction dimension is taken for this research study and the dimensions are given below in figure1.

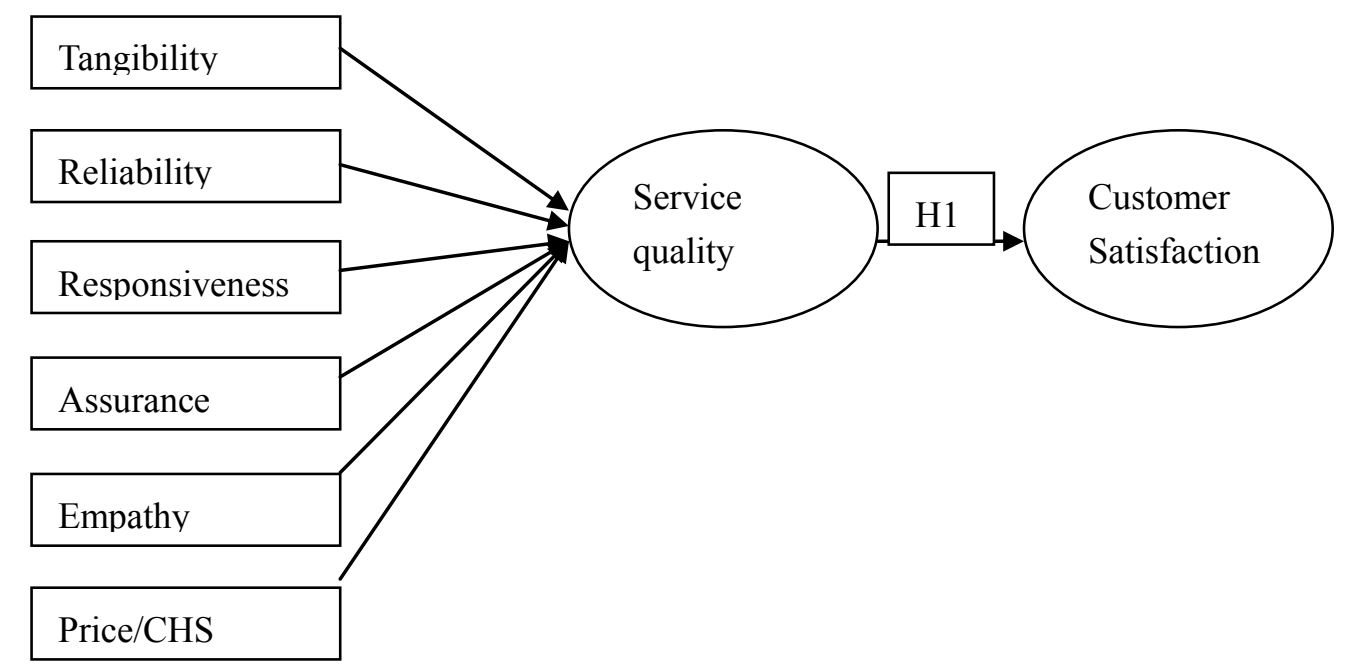

Figure1: SERVQUAL Model

An overview of the BSR Procedures is given below and the results of using the adaptive BSR methodology on data obtained form the customer survey using the servqual dimensions are then presented. The final section summarizes the findings and provides a number of implications for research and practice.

\subsection{Empirical Findings}

Correlation matrices for the banks along with the means and standard deviations for the 25 items of 5 servqual dimensions are given in Table 1. Table 2 reports the standardized regression coefficients resulting from the BSR and OLS procedures. Since the BSR coefficients have a multivariate t- distribution, and given the relatively large sample size, a parameter estimate is considered to be statistically significant in this study if it is more than twice its standard error. Table 1 Indicates that each Servqual items are positively correlates 
with the criterion of overall service quality. All Correlations between Servqual items are positive as well. Therefore, it is reasonable to expect the signs of the regression coefficients to be positive. Table 2 shows that a significant determinate of overall preference for banks based on OLS estimation is that the bank shows sincere interest in solving the customers problems, employees were busy to respond to customer request and banks should give their customers personal attention are very significant.

It is evident that more specialized methods of estimation are needed to account directly for the conditions that may characterize a model involving customers' perceptions on Service quality. The adaptive BSR framework outlined here provides a random variable approach to estimation where all variables are, at best, assumed to be fallible measures of underlying [latent] variables. The usefulness of the methodology to model customers' perceptions on Service quality is illustrated below.

BSR $[\mathrm{m}]$ estimated for banks were derived from a common factor model with $\mathrm{m}=0,1,2,3$ common factors, but the significant BSR weights for different choices of $\mathrm{m}$ are seen to be quite similar. So $\mathrm{m}=0$ and 3 are choosen ( Since $\mathrm{m}=1$ and 2 are having almost same standard errors) and are shown in table 2. Various methods for choosing a value for $\mathrm{m}$ in a common factor model are available to researchers (Akaike 1987; Bozdogan 1990; joreskog 1969; Lawley and Maxwell 1971). In the context of Bayesian structural regression, where a common factor model is used as an approximate structural representation for the prior mean of $\sum$, the selection of may not play a critical role in obtaining reliable regression structural representation estimates. As evidenced in the simulations discussed earlier, a reasonable choice for the number of common factors should suffice in most applications. Table 1 show that the seven largest eigen values of the joint predictor -criterion correlation matrix for banks exceed unity and appear to be relatively larger than the remaining 18 eigen values. Thus, in modeling customers' perceptions on servqual items for banks it is assumed that the 25 variates can be regarded as observed indicators of two latent measures-the two common factors. 
The goodness of fit index $[1-\mathrm{w}]$ computed from the data for the focal bank is 0.68 . An index of the magnitude indicates that the BSR estimates rely rather strongly on the parameter estimates associated with the prior common factor model. In this case it is reasonable to examine the latent measures corresponding to the structural model for the prior mean of $\mathrm{E}$. The fact that all the correlation coefficients between predictor variables and the criterion variable in table 1 are positive indicates that retail customers who rate a bank above a average on anyone of the Servqual variables also tend to give that bank an above average overall Service quality rating. The structural goodness of fit index is relatively high for the banks taken for the study. Nevertheless, in the case, complete reliance on the prior structural model is not supported by the data. The adaptive BSR methodology will derive the significant determinants of overall service quality for the banks by automatically discounting the structural information to the degree warranted by the data.

The regression results of the Banks are given in the Table 2. The BSR estimates in Table 2 indicate that the interest on solving customer problems, giving personal attention to customers and understanding the needs of the customers are the main factors evolved from the BSR estimates. Also, from a practical point, the significant determinants of preference on service quality of a bank may be ordered according to their absolute t- ratios. This may be useful when a bank is interested in identifying priorities regarding its service delivery approaches.

\section{Conclusion}

There are several interesting conclusion and research implications drawn from these results. One of the primary causes of service quality design failure is the lack of understanding of the evolving need and preferences of targeted customers (Bateson 1990). Also, important characteristics of a successful service firm are its ability to ascertain its competitive position with in a target market and satisfy the customers better than the competitor ( heskett 1990). The results of the study reveal a high degree of concordance between the various items of 
servqual items which in turn speaks of service quality delivery.

Banks may attempt to reposition itself by restructuring its service delivery system to enhance the Servqual items in the areas of service quality. Dimensions of Servqual items such as solving the customer problems, service delivery on time, quick response to customer request, safe transactions, personal attention and understanding the needs of the customer appear to be fertile areas for future inquiry. Khazeh and Decker (1992-93) argue that the perceived differences amongst banks are true determinants of service quality and most the Servqual items captured in the BSR estimates confirms the same.

So future research a cross sectional design can be undertaken between a focal bank with the competing banks, which bench marks the determinants of service quality. In summary the findings here gives the evidence of the appropriateness of the adaptive BSR procedures in Service quality applications. The effectiveness of the approach in both an absolute and a relative sense has been discussed. It is expected that the methodology may improve the treatment of model building and applied linear prediction in future service quality applications, especially in the general area of consumer research.

\section{References}

Akaike,H. (1987). Factor Analysis and AIC. Psychometrika, 52(3):317-332.

Anderson, E.W. and M.W. Sullivan (1993). The Antecedents and consequences of customer satisfaction for firms. Marketing Science, 12(2): 125-143.

Aldlaigan, A. and Buttle, A. (2002). SYSTRA-SQ: a new measure of banks service quality. International Journal of Service Industry Management, Vol. 13 No. 4, pp. 362-81.

Anderson, E., Fornell, C. and Lehmann, D. (1994). Customer satisfaction and word of mouth. Journal of Service Marketing, Vol. 1 No. 1, pp. 5-17.

Bateson, J .E.G. (1990). Evaluating the role and place of Marketing in service firms. Service Management effectiveness.13(2):324-342. 
Bahia, K. and Nantel, J. (2000). A reliable and valid measurement scale for the perceived service quality of banks. The International Journal of Bank Marketing, Vol.18 No.2, pp. 84-91.

Baker,D. \& Crompton,J. (2000). Quality, satisfaction and behavioural intentions. Annals of Tourism Research, Vol .7 No. 27, PP. 785-804.

Bearden, W.O. and J.E. Teel (1983). Selected Determinants of customer satisfactionand complaint reports. Journal of Marketing research, 20,21-28.

Bolton, R.N. and J.H. drew (1991a). A longitudinal Analysis of the impact of service changes on customer attitudes. Journal of Marketing, 55:1-9.

Bolton, R.N. and J.H. drew (1991b). A Multistage model of customers Assessment of service quality and value. Journal of Consumer Research, 17:375-384.

Bloemer , J., Ko de Ruyter. \& Wetzels, M. (1999). Linking perceived service quality and service loyalty: A multi-dimensional perspective. Journal of Marketing,Vol .7 No. 33, pp.1082-1106.

Bloemer,J., Ruyter,K and Peeters,P. (1998). Investigating drivers of bank loyalty: the complex relationship between image, service quality and satisfaction. International Journal of Bank Marketing, Vol. 16 No. 7, pp. 276-86.

Caruana,A. (2002). Service loyalty: the effects of service quality and the mediating role of customer satisfaction. European Journal of Marketing, Vol. 36 Nos 7/8, pp. 811-28.

Cardozo, R. N. (1965). An Expwerimental study on Customer effort, Expectation and Satisfaction. Journal of Marketing Research, 2:244-249.

Chen, C.F.(1979). Bayesian Inference for a Normal Dispersion Matrix and its applications to Stochastic Multiple Regression Analysis. Journal of Royal Statistical Society, Series B, 41:235-248.

Cronin, J.J.Jr. and Taylor, S.A. (1992). Measuring service quality: a reexamination and extension. Journal of Marketing, Vol. 56 July, pp. 55-68.

Douglas, L., \& Connor, R. (2003). Attitudes to service quality - The expectation gap. Nutrition \& Food Science,33(4), 165-172.

Duffy, J. A., Duffy, M., \& Kilbourne, W. (2001). A comparative study of resident, family, and 
administrator expectations of service quality in nursing homes. Health Care Management Review, 26(3), 75-85

Khazeh, K and W.K. Decker (1992-93). How customers choose Banks. Journal of Retail Banking, 14(winter:41-44.

LaTour S.A. and N.C. Peat (1979). Conceptual and Methodological Issues in consumer Satisfaction Research. Advances in Consumer Research:431-437

Nunally,C. J. (1978), Psychometric Theory, McGraw-Hill, New York, NY.10.Oliver,R.(1997). Satisfaction: A behavioral perspective on the consumer. New York:McGraw Hill.

Oliver, R.L. (1980). A cognitive Model of the antrecedents and Consequences of Satisfaction Decisions. Journal of Marketing Research, 17:460-469

Oliver, R.L. and W. DeSarbo (1988). Response determinants in satisfaction judgements. Journal of Consumer research, 14(March):495-507.

Parasuraman, A., Zeithaml, V. A., \& Berry, L. L. (1985). A conceptual model of service quality and its implications for future research. Journal of Marketing, 49,41-50.

Parasuraman, A., Zeithaml, V. A., \& Berry, L. L. (1988).SERVQUAL: A multiple-item scale for measuring con- sumer perceptions of service quality. Journal of Retailing,64, 12-40. Parasuraman, A., Zeithaml, V. A., \& Berry, L. L. (1994). Re- assessment of expectations as a comparison standard in measuring service quality: Implications for further re- search. Journal of Marketing, 58, 111-124.

Pruzek, R.M. and G. M. lepak (1992). Weighted Structural Regression: A broad class of adaptive methods for improving linear predictions. Multivariate Behavioural Research,21(1):95-129.

Spreng, R.A. and MacKoy, R. D. (1996). An empirical examination of a model of perceived service quality and satisfaction. Journal of Retailing, Vol. 72 No. 2, pp. 201-14.

Sureshchandar,G., Rajendran,C. and Anantharaman,R. (2002b). The relationship between service quality and consumer satisfaction - a factor specific approach. Journal of Services Marketing, Vol. 16 No. 4, pp. 363-79. 
Teas,R. (1993). Expectations, performance evaluation, and consumers' perceptions of quality. Journal of Marketing, Vol. 57 October, pp. 18-34.

Tse, D.K. and P.C. Wilton (1988). Models of consumer satisfaction formation: An Extension. Journal of Marketing Research, 25(May):204-212.

Woodside,A.G., Frey,L.L. and Daly,R.T. (1989). Linking service quality, customer satisfaction and behavioural intention. Journal of Health Care Marketing, Vol. 9 No. 4, pp. $5-17$

Westbrook, R.A. (1981). Sources of consumer Satisfaction with retail outlets. Journal of Retailing, 57(fall):68-85.

Yi.Y.(1990). Critical Review of Consumer Satisfaction. Review of Marketing, 1990:68-123.

Zeithaml,V.A. and Bitner,M.J. (2003). Services Marketing", Integrating Customer Focus Across the Firm. New York: McGraw-Hill.

Zeithaml,V.A. (1988). Consumer perceptions of price, quality, and value: a means-end model and synthesis of evidence. Journal of Marketing, Vol. 52 No. 3, pp. 2-22.

Zeithaml, V.A. (2000). Service quality, profitability, and the economic worth of customers: what we know and what we need to learn. Journal of the Academy of Marketing Science, Vol. 28 No. 1, pp. 67-85.

Zeithaml,V. A., Berry, L. L. and Parasuraman, A. (1996). The behavioral consequences of Service quality. Journal of Marketing, Vol. 60 April, pp. 31-46.

Zeithaml,V., Parasuraman,A. and Berry,L. (1990). Delivering Quality Service. Free Press, New York, NY 


\section{Macostitink

\section{Correlation Matrix ( $n=300)$}

\begin{tabular}{|c|c|c|c|c|c|c|c|c|c|c|c|c|c|c|c|c|c|c|c|c|c|}
\hline Over All Service Quality & 1 & & & & & & & & & & & & & & & & & & & & \\
\hline Have State of the Art Technology & -0.11 & 1.00 & & & & & & & & & & & & & & & & & & & \\
\hline Physical Facilities -Visually Appealing & 0.08 & 0.16 & 1.00 & & & & & & & & & & & & & & & & & & \\
\hline Materials(E.g. Brochures and Statements) visually Appealing & -0.11 & 0.08 & -0.09 & 0.11 & 1.00 & & & & & & & & & & & & & & & & \\
\hline Promises to do so by a certain time, they will do so. & 0.25 & 0.04 & 0.09 & 0.08 & 0.03 & 1.00 & & & & & & & & & & & & & & & \\
\hline \multicolumn{22}{|l|}{ Customer have a problem, excellent banks will show sincere } \\
\hline interest in solving it. & -0.14 & 0.01 & 0.16 & -0.01 & 0.00 & 0.10 & 1.00 & & & & & & & & & & & & & & \\
\hline The services of a bank should be performed right the first time & -0.15 & -0.12 & -0.07 & 0.21 & 0.05 & -0.03 & 0.06 & 1.00 & & & & & & & & & & & & & \\
\hline Bank should deliver the services on time & -0.11 & 0.20 & -0.05 & 0.03 & 0.06 & 0.11 & 0.19 & 0.06 & 1.00 & & & & & & & & & & & & \\
\hline Bank should insist on Error free Records & -0.07 & -0.06 & -0.04 & 0.15 & 0.07 & -0.13 & 0.09 & 0.18 & 0.11 & 1.00 & & & & & & & & & & & \\
\hline Tell customers when exactly the services will be performed & 0.01 & 0.08 & 0.14 & 0.12 & 0.02 & 0.20 & 0.13 & 0.07 & -0.04 & 0.07 & 1.00 & & & & & & & & & & \\
\hline Employees in a bank should give prompt service. & -0.03 & 0.10 & 0.13 & -0.07 & -0.09 & 0.00 & 0.06 & -0.02 & 0.20 & -0.11 & 0.07 & 1.00 & & & & & & & & & \\
\hline Employees should always be willing to help customers & -0.07 & 0.09 & 0.12 & 0.03 & -0.06 & -0.09 & 0.03 & 0.05 & -0.06 & 0.05 & 0.03 & 0.24 & 1.00 & & & & & & & & \\
\hline Behaviour of employees should instill confidence in customers & -0.28 & 0.09 & -0.15 & 0.06 & 0.01 & -0.02 & 0.10 & 0.15 & 0.14 & 0.04 & 0.18 & 0.03 & 0.00 & 0.41 & 1.00 & & & & & & \\
\hline Customers of a bank should feel safe in all their transaction & -0.38 & 0.24 & 0.10 & 0.15 & 0.17 & -0.02 & 0.10 & 0.23 & 0.34 & 0.13 & 0.04 & 0.20 & -0.03 & 0.25 & 0.27 & 1.00 & & & & & \\
\hline Employees should consistently be courteous with customers & -0.02 & -0.05 & 0.04 & 0.07 & 0.07 & 0.22 & 0.12 & -0.05 & 0.26 & 0.13 & 0.21 & -0.10 & -0.04 & 0.00 & 0.02 & 0.04 & 1.00 & & & & \\
\hline \multicolumn{22}{|l|}{ Employees should have the knowledge to answer customers } \\
\hline questions & -0.36 & 0.13 & 0.04 & 0.33 & 0.08 & 0.14 & 0.24 & 0.26 & 0.14 & 0.23 & 0.19 & 0.15 & 0.15 & 0.21 & 0.19 & 0.37 & 0.17 & 1.00 & & & \\
\hline A bank should give customers individual attention & -0.26 & 0.13 & 0.01 & 0.36 & 0.05 & 0.11 & 0.02 & 0.15 & 0.10 & -0.06 & 0.02 & 0.03 & -0.06 & 0.19 & 0.08 & 0.32 & -0.11 & 0.38 & 1.00 & & \\
\hline The operation hours of the bank should be convenient & -0.41 & 0.13 & -0.11 & 0.29 & 0.30 & 0.09 & 0.29 & 0.11 & 0.17 & 0.13 & 0.08 & 0.02 & 0.04 & 0.24 & 0.36 & 0.26 & 0.16 & 0.37 & 0.15 & 1.00 & \\
\hline Employees of a bank should give their customers personal & -0.33 & 0.02 & -0.16 & 0.13 & 0.06 & -0.12 & 0.02 & 0.29 & 0.27 & 0.22 & -0.04 & 0.10 & 0.11 & 0.12 & 0.09 & 0.47 & 0.13 & 0.36 & 0.31 & 0.23 & 1.00 \\
\hline
\end{tabular}




\begin{tabular}{|c|c|c|c|c|c|c|c|c|c|c|c|c|c|c|c|c|c|c|c|c|c|c|c|}
\hline \multirow[b]{2}{*}{ attention } & & & & & & & & & & & & & & & & & & \multicolumn{6}{|c|}{$\begin{array}{r}\text { Enterprise Risk Management } \\
\text { ISSN 1937-7916 } \\
\text { 2010, Vol. 1, No. 1: E9 }\end{array}$} \\
\hline & & & & & & & & & & & & & & & & & & & & & & & \\
\hline A bank should have a customers best interest at heart & -0.25 & 0.10 & 0.05 & 0.25 & 0.05 & -0.01 & 0.11 & 0.26 & 0.37 & 0.18 & 0.00 & -0.04 & 0.02 & 0.21 & 0.15 & 0.40 & 0.19 & 0.52 & 0.32 & 0.23 & 0.25 & 1.00 & \\
\hline Bank employees should understand the specific nee & & & & & & & & & & & & & & & & & & & & & & & \\
\hline customers & -0.19 & 0.11 & 0.03 & 0.09 & -0.18 & -0.04 & 0.25 & 0.11 & 0.46 & 0.02 & 0.07 & 0.17 & -0.07 & 0.15 & 0.21 & 0.24 & 0.14 & 0.17 & 0.18 & 0.08 & 0.23 & 0.34 & 1.00 \\
\hline MEAN & 4.23 & 3.73 & 3.51 & 3.77 & 3.51 & 3.5 & 3.24 & 3.34 & 4.2 & 3.13 & 3.27 & 3.44 & 3.16 & 3.79 & 4.11 & 3.37 & 3.75 & 3.44 & 3.39 & 3.45 & 3.26 & 3.36 & 3.38 \\
\hline Sample SD & 0.633 & 0.694 & 0.810 & 0.886 & 0.893 & 0.759 & 0.842 & 0.913 & 0.752 & 0.884 & 1.090 & 0.857 & 1.089 & 0.795 & 0.764 & 0.812 & 0.880 & 0.967 & 0.898 & 0.770 & 0.906 & 0.81 & 0.83 \\
\hline Eigen Values & 6.214 & 2.742 & 2.091 & 1.776 & 1.670 & 1.527 & 1.267 & 1.192 & 0.990 & 0.811 & 0.743 & 0.652 & 0.611 & 0.494 & 0.472 & 0.454 & 0.397 & 0.352 & 0.303 & 0.273 & 0.234 & 0.312 & 0.294 \\
\hline
\end{tabular}




\section{Bank 2}

\section{Standard Regression Co-efficient ( $\mathbf{n}=\mathbf{3 0 0}$ )}

\begin{tabular}{|c|c|c|c|c|c|c|}
\hline \multirow[b]{3}{*}{ Image Criteria } & & & \multicolumn{4}{|c|}{ Bayesian Structural Regression } \\
\hline & \multicolumn{2}{|c|}{ Ordinary Least Squares } & \multicolumn{2}{|c|}{$m=0$} & \multicolumn{2}{|c|}{$m=3$} \\
\hline & Coefficient & $\mathrm{t}$-value & Coefficient & t-value & Coefficient & t-value \\
\hline Have State of the Art Technology & -0.186 & -2.114 & -0.095 & -1.674 & 0.005 & -1.054 \\
\hline Physical Facilities -Visually Appealing & -0.174 & -1.027 & -0.114 & -0.587 & -0.064 & 0.033 \\
\hline Employees Neat Appearance & 0.118 & 0.650 & 0.143 & 1.090 & 0.152 & 1.710 \\
\hline Materials(E.g. Brochures and Statements) visually Appealing & -0.141 & -0.986 & 0.028 & -0.546 & 0.041 & 0.074 \\
\hline Promises to do so by a certain time, they will do so. & -0.054 & -0.323 & 0.012 & 0.117 & 0.009 & 0.737 \\
\hline Customer have a problem, excellent banks will show sincere interest in solving it. & -0.474 & $2.856^{*}$ & -0.245 & $2.456^{*}$ & -0.200 & 1.796 \\
\hline The services of a bank should be performed right the first time & -0.182 & -1.162 & 0.036 & -0.722 & 0.052 & -0.102 \\
\hline Bank should deliver the services on time & -0.306 & $2.329 *$ & 0.006 & 1.789 & 0.094 & 1.169 \\
\hline Bank should insist on Error free Records & -0.002 & -0.033 & 0.051 & 0.407 & 0.105 & 1.027 \\
\hline Tell customers when exactly the services will be performed & 0.099 & 0.778 & 0.216 & 1.218 & 0.751 & 1.838 \\
\hline Employees in a bank should give prompt service. & -0.126 & -1.142 & 0.046 & -0.702 & 0.111 & -0.082 \\
\hline Employees should always be willing to help customers & 0.023 & 0.304 & 0.381 & 0.744 & 0.496 & 1.364 \\
\hline Employees never too busy to respond to customers request & -0.171 & $2.174 *$ & -0.006 & 1.594 & 0.010 & 0.974 \\
\hline Behaviour of employees should instill confidence in customers & -0.023 & -0.354 & 0.194 & 0.086 & 0.256 & 0.706 \\
\hline Customers of a bank should feel safe in all their transaction & 0.098 & 1.244 & 0.328 & 1.684 & 0.410 & $2.404 *$ \\
\hline Employees should consistently be courteous with customers & -0.008 & -0.103 & 0.123 & 0.337 & 0.210 & 0.957 \\
\hline Employees should have the knowledge to answer customers questions & 0.058 & 0.781 & 0.294 & 1.221 & 0.351 & 1.841 \\
\hline A bank should give customers individual attention & 0.005 & 0.047 & 0.306 & 0.487 & 0.425 & 1.107 \\
\hline The operation hours of the bank should be convenient & -0.001 & -0.009 & 0.154 & 0.431 & 0.196 & 1.051 \\
\hline Employees of a bank should give their customers personal attention & 0.215 & $2.858^{*}$ & 0.496 & $3.298^{*}$ & 0.490 & $3.918^{*}$ \\
\hline A bank should have a customers best interest at heart & 0.024 & 0.291 & 0.287 & 0.731 & 0.235 & 1.351 \\
\hline
\end{tabular}


0.155

1.795

$0.5212 .535^{*}$

2010, Vol. 1, No. 1: E9

Bank offers competitive interest rates

$-0.029$

$-0.326$

$0.102 \quad 0.114$

$0.8102 .855^{*}$

Squared Multiple Correlation

0.671

* A Parameter estimate is significant if it is more than twice its standard error 


\section{Macrothink}

Descriptive Statistics

\begin{tabular}{|c|c|c|c|c|c|}
\hline & $\mathrm{N}$ & Mean & Std. Deviation & \multicolumn{2}{|c|}{ Skewness } \\
\hline & Statistic & Statistic & Statistic & Statistic & Std. Error \\
\hline MODERN LOOKING EQUPIMENTS & 100 & 4.2300 & .63333 & -.228 & .241 \\
\hline MODERN LOOKING AMENITIES & 100 & 3.7300 & .69420 & -.135 & .241 \\
\hline EMPLOYEE APPREANCE & 100 & 3.5100 & .81023 & .083 & .241 \\
\hline MATERIALS VISUALLY APPEALING & 100 & 3.7700 & .88597 & -.240 & .241 \\
\hline PROMISES TO DO SOMETHING & 100 & 3.5100 & .89324 & -.074 & .241 \\
\hline SINCERE INTEREST TO CUSTOMER PROBLEM & 100 & 3.5000 & .75879 & -.283 & .241 \\
\hline PERFORM SERVICE RIGHT AT THE FIRST TIME & 100 & 3.2400 & .84232 & .035 & .241 \\
\hline SERVICE AT THE TIME THEY PROMISE & 100 & 3.3400 & .91254 & -.489 & .241 \\
\hline INSIST ON ERROR FREE RECORD & 100 & 4.2000 & .75210 & -.785 & .241 \\
\hline TELL CUSTOMER EXACTLY WHEN SREVICE PERFORMED & 100 & 3.1300 & .88369 & -.439 & .241 \\
\hline GIVE PROMPT SERVICE TO CUSTOMER & 100 & 3.2700 & 1.09041 & -.273 & .241 \\
\hline WILLING TO HELP CUSTOMER & 100 & 3.4400 & .85658 & -.302 & .241 \\
\hline EMPLOYEES RESPOND TO CUSTOMER REQUEST & 100 & 3.1600 & 1.08916 & -.182 & .241 \\
\hline EMPLOYEE BEHAVIOUR INSIST CONFIDENCE & 100 & 3.7900 & .79512 & -.710 & .241 \\
\hline CUSTOMER FEEL SAFE IN THEIR TRANSACTION & 100 & 4.1100 & .76403 & -.328 & .241 \\
\hline CONSISTENTLY COURTEOUS WITH CUSTOMER & 100 & 3.3700 & .81222 & -.088 & .241 \\
\hline KNOWLEDGE TO ANSWER CUSTOMER QUESTION & 100 & 3.7500 & .88048 & -.844 & .241 \\
\hline BANK GIVE CUSTOMER INDIVIDUAL ATTENTION & 100 & 3.4400 & .96735 & -.647 & .241 \\
\hline
\end{tabular}




\section{Macrothink Institute ${ }^{\mathrm{m}}$}

CONVENIENT OPERATING HOURS

EMPLOYEES GIVE CUSTOMER PERSONAL ATTENTION

CUSTOMER'S BEST INTEREST AT HEART

UNDERSTAND SPECIFIC NEEDS OF CUSTOMER

COMPETITIVE INTERST RATES

REASONABLE SERVICE CHARGE

COMPLAINT HANDLING SYSTEM

OVERALL SERVICE QUALITY

Valid N (listwise)
Enterprise Risk Management

ISSN 1937-7916

2010, Vol. 1, No. 1: E9 